\title{
Design and Implementation of Position Estimator Algorithm onVoice Coil Motor
}

\author{
Mahesh S. Shewale \\ Dept.of Mechanical Engineering, \\ Purdue School of Engineering \& Technology, IUPUI, \\ Indianapolis,USA \\ mshewale@iupui.edu
}

\author{
Dr. Ali Razban \\ Dept.of Mechanical Engineering, \\ Purdue School of Engineering \& Technology, IUPUI, \\ Indianapolis,USA \\ arazban@iupui.edu
}

\author{
Dr. Suhas P. Deshmukh \\ Dept.of Mechanical Engineering, \\ Government College of Engineering, \\ Chandrapur,India \\ suhas.deshmukh@gmail.com
}

\author{
SharadS. Mulik \\ Dept.of Mechanical Engineering, \\ G. H. Raisoni College of Engineering \\ \& Management, Pune, India \\ sharadmulik@gmail.com
}

\author{
Hrishikesh B. Zambare \\ Dept.of Mechanical Engineering, \\ Purdue School of Engineering \& Technology, \\ IUPUI, \\ Indianapolis,USA \\ hzambare@umail.iu.edu
}

\begin{abstract}
Voice Coil Motors (VCMs) have been an inevitable element in the mechanisms that have been used for precise positioning in the applications like 3D printing, microstereolithography, etc. These voice coil motors translate in a linear direction and require a high accuracy position sensor that amounts for a major part in the budget. In this research work, an effort has been made to design and implement an algorithm that would predict the displacement of VCM and eliminate the need of high cost sensors. VCM was integrated with dSPACE DS1104 R\&D controller via linear current amplifier (LCAM) which acts as a driver circuit for VCM. Sine input was given to VCM with various amplitude and frequency and the corresponding displacement is measured by using linear variable differential transformer (LVDT). The position estimator algorithm is also implemented at the same time on VCM and its output is compared with that of LVDT. It is observed that there is $97.8 \%$ accuracy in between algorithm output and LVDT output. Further, PID controller is used in integration with the novel algorithm to minimize the error. The estimator algorithm is tested for various amplitudes and frequencies and it is found that it has a very good agreement of $99.2 \%$ with the actual displacement measured with the help of LVDT.
\end{abstract}

IndexTerms-LVDT, dSPACE DS1104, VCM, PID, position estimator

\section{INTRODUCTION}

In today's industrial era where human workers are being replaced by highly intelligent automated systems, use of several types of sensors \& actuators in these systems for industrial application is an inevitable criterion [1]. Different types of actuators are used for executing the actions in the industrial processes. Types of motors such as induction motors, stepper and servo motors are used for rotary actuation purposes i.e. to provide actuation in rotary motion [2]. AC or DC induction motors are utilized where speed of rotation is an essential criterion for example in lathe machines, drilling machines, etc. [3]. Stepper motors are used where the angular displacement of the rotating shaft is an important aspect to be considered. These motors can have high resolution in the range of 10000 pulses per revolution enabling them to achieve highly precise angular motion [4]. Servo motors are similar to the above mentioned except they have a facility of feedback signal from the sensor mounted on output shaft $[5,6]$. This sensor can either be used to measure speed or angular displacement or both for a particular motor shaft. Therefore, several advancements in rotary actuators have been achieved till date [7].

However, if linear actuators are concerned, some devices are developed with the help of rotary actuators. Some traditional mechanisms are used for the application of linear or translatory motion such as lead screw, ball screw, hydraulic and pneumatic devices, etc. [8,9]. But these mechanisms have some drawbacks such as friction, backlash and wear of components associated with the system. Also, these mechanisms need to be lubricated and they exhibit lot of hysteresis error [10-12]. As far as lead crews and ball screw mechanisms are concerned, they have very low speed of operation in translatory motion and low efficiency, whereas the possibility of leakages in hydraulic and pneumatic devices is a vital aspect to be considered. Gear trains like worm drive and rack $\&$ pinion need to be lubricated and wear out after certain amount of time [13].

To overcome these difficulties, we come up with a novel solution of voice coil actuators. Voice coil motors are linear motors basically used in speakers and headphones to convert electrical signals into appropriate vibrations and thus produce sound waves [14, 15]. Also, they are extensively utilized in motion head inside the hard disk drives which are used to store data in computers. These are light duty applications in which very less force is needed to be generated by voice coil motors [16]. In the industrial applications, large forces are needed to be generated. To achieve this, we need to make proper changes in the design of voice coil motor. This voice coil motor can be

This is the author's manuscript of the article published in final edited form as: 
widely used in the sectors where precise positioning is inevitable part in the range of microns[17-19].

In this paper, an effort has been made to elaborate the design procedure, finite element analysis, mechatronic integration and experimental investigation of voice coil motor. Section II describes design of voice coil motor based upon the requirements. Section III describes the experimental layout necessary for the experimentation. Section IV puts forward the design and implementation of position estimator algorithm in MATLAB Simulink. Section V displays the results and outcomes of this implementation. Section VI concludes the research paper in accordance with the objectives.

\section{Design of Voice CoIL Motor}

Voice coil actuators arc direct drive, defined motion equipmentwhichutilize a permanent magnet field and a coil winding or conductor to yield a force which is proportional to the current flowingthrough the coil. These non-commutated electromagnetic devices are utilized in translatory and rotary motion functionsthat require linear force output and high acceleration or high frequency operation [20].

The working principle of a voice coil motor isgoverned by the Lorentz Force Principle. This law of says that if a current carrying conductor is kept in a magnetic field, a force will actupon it. The magnitude of this force is given by:

$$
\mathrm{F}=\mathrm{kBLIN}
$$

Where $\mathrm{k}$ - constant, B - magnetic flux density, I - current flowing through the coil, L - length of the conductor, $\mathrm{N}-$ number of conductors [21].

Figure 1 is a simplified example of this law. Here, the direction of the force generated depends on the direction of current and magnetic field vectors. Especially, it is the crossproduct of the two vectors. Ifcurrent flow is reversed, the directionof the force on the conductor will alsoreverse. Produced force is proportionateto input current, if the magnetic field strength andconductor length are unchanged, as theyare in a voice coil motor.

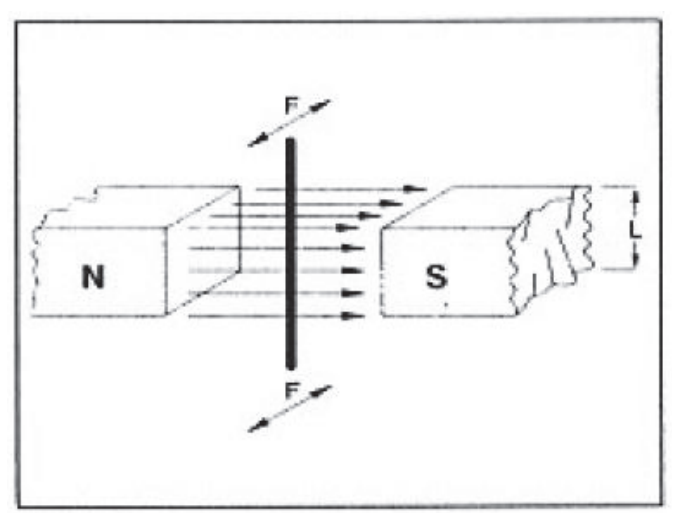

Fig. 1. Linear Voice Coil Actuator

In its simplemanner, a linear voicecoil actuator is a tubular coil of wire located within a radially occurring magnetic field, as shown in Figure 2. This magneticfield is generated by permanent magnets fixed on ferromagnetic cylinder, organizedsuch that magnets in front of the coilhavesimilar polarity. An innercore of ferromagnetic material setalong the axial centerline of the coil,joined at one end to the permanentmagnet assembly, is used to completethe magnetic circuit. The force producedin axial direction on coil when current isflowing through coil generatesrelative displacement between field assembly and coil. It is subject to the condition thatproviding forceis huge enough to compensateinertia, friction and any additional forces that arise from massesfixed to coil.

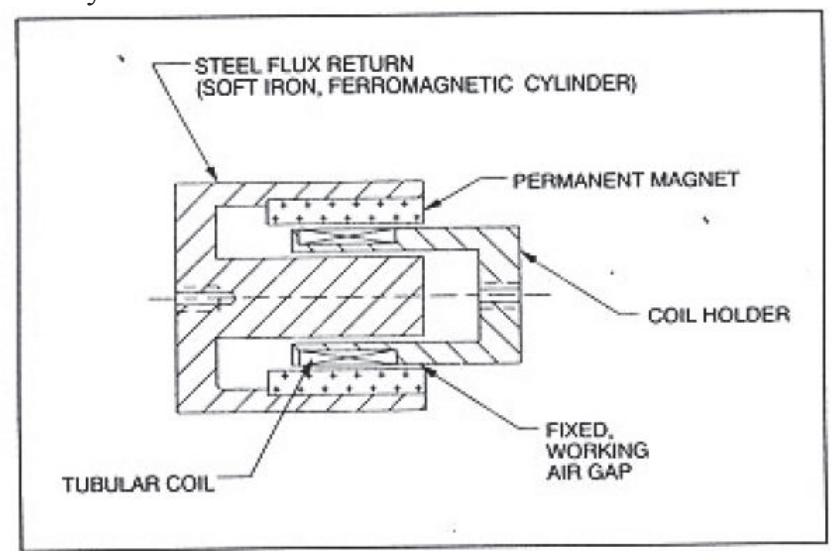

Fig. 2: Linear Voice Coil Actuator

As shown in Figure 3, the CAD model for voice coil motor is created using ProECreo modelling software. Figure 4 shows the exploded view of voice coil motor assembly in which all the components of voice coil motor are shown. Initially, permanent magnet is placed inside the housing made of aluminum and it is fixed to the housing with the help of alan screws. One end of bobbin on which a coil made of copper is wound and it is enclosed in the magnet. Other end of cylindrical bobbin is connected to the output shaft through coil holder. To maintain the bobbin exactly at the center, we use flexural spring made of beryllium copper. To fix this flexural bearing to the housing, we use a ring on which holes are made at its periphery to facilitate insertion of screws for fixing. Horizontal slots are made at the extended base of the housing in order to attach it to the optical table.

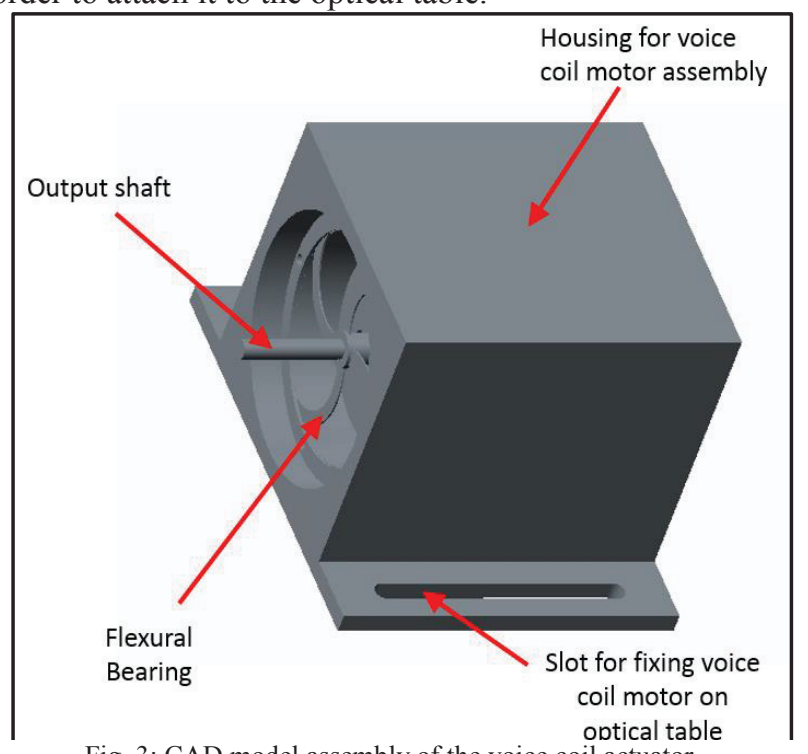

Fig. 3: CAD model assembly of the voice coil actuator 


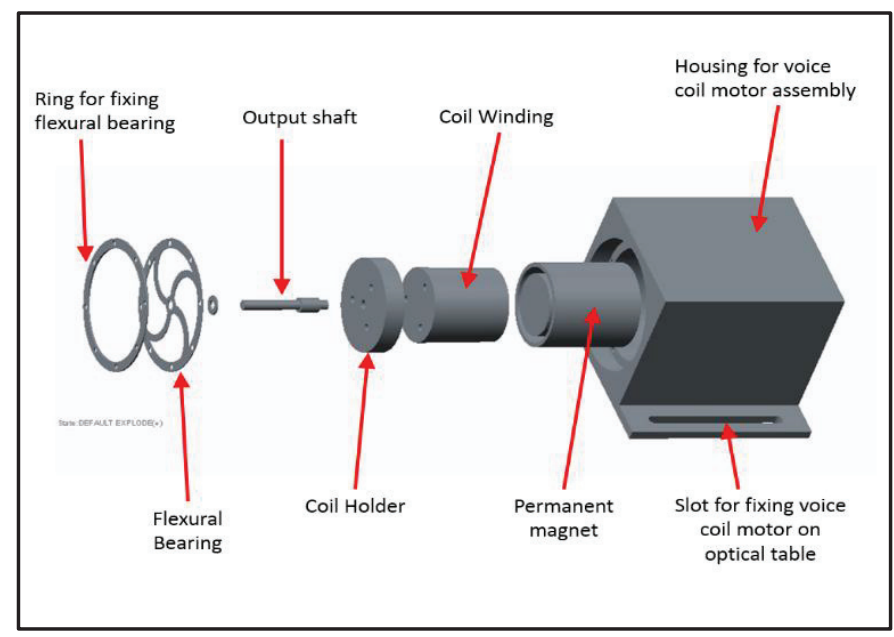

Fig. 4: Exploded view of voice coil motor assembly

Figure 5 shows the manufactured voice coil motor alongwith its output shaft and LVDT core is connected to it for displacement measurement purpose.

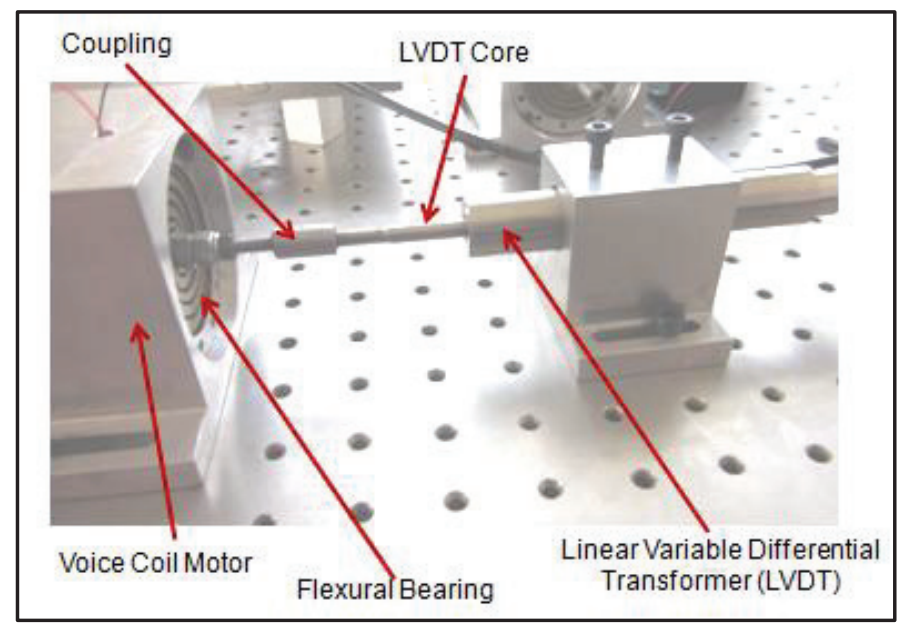

Fig. 5: Manufactured voice coil actuator and Experimental Setup

\section{MECHATRONIC INTEGRATION}

It is essential for voice coil motor that it should be operated through controller. We use dSPACE DS1104 R\&D controller to provide amplitude and frequency of voice coil actuation. When we provide amplitude and frequency in ControlDesk GUI, the control logic in Simulink converts it into appropriate voltage signal which is given to linear current amplifier (LCAM) through CLP1104 connection board. This connection board facilitates receiving and sending analog, digital, PWM and serial communication to the controller. The voltage signal from dSPACE is converted into current with the help of LCAM. It works as a driver circuit for voice coil motor. VCM gives out desired linear displacement at the output shaft as per the provided amplitude and frequency. This displacement is measured with the help of linear variable differential transformer (LVDT) which has resolution in microns. LVDT generates a voltage proportional to the displacement of core of LVDT and this feedback voltage signal is given to dSPACE controller through CLP1104 connection board. This mechatronic integration is explained in Figure 6 below.

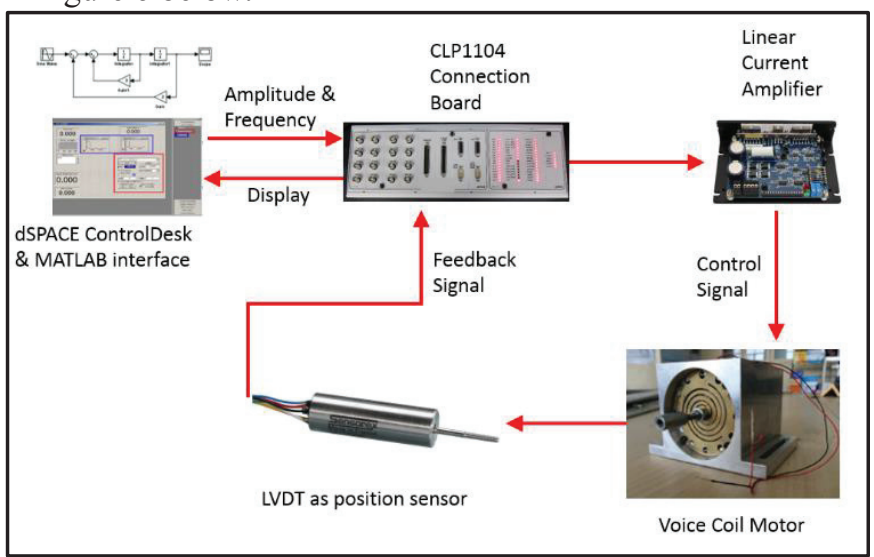

Fig. 6: Layout of Experimental Setup

\section{DESIGN \& IMPLEMENTATION OFPOSITION ESTIMATOR ALGORITHM}

VCM used in this research work consists of permanent magnet and current carrying coil. Principle of working of linear motor is similar to voice coil used in speakers. As current passes through coil, mechanical force is generated, and direction of force depends on the direction of current. Construction of linear voice coil motor is shown in Figure 7and also equivalent circuit diagram is shown as subfigure.

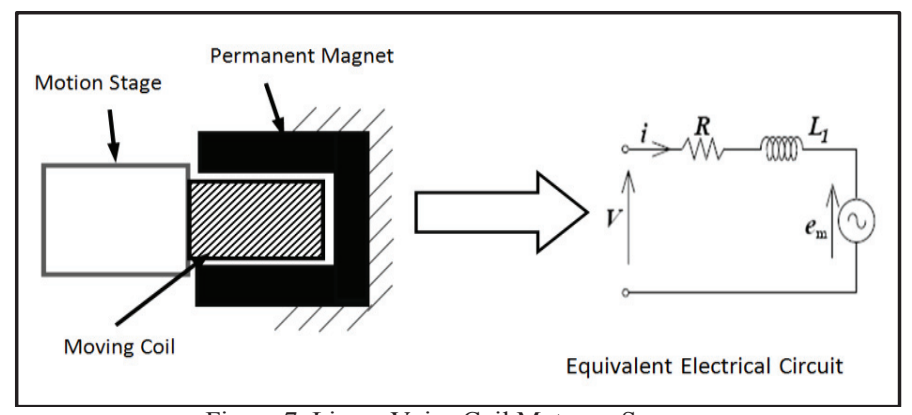

Figure 7: Linear Voice Coil Motor as Sensor

Equation of electrical circuit is given by relation,

$$
V_{s S}=R_{i} I_{a}+L_{i} \frac{d I_{a}}{d t}+\alpha \frac{d x}{d t}
$$

Where, $V_{\text {ss }}$ is supply voltage, $R_{i}$ is resistance of coil, $L_{i}$ is inductance of coil, $\alpha$ is motor constant, $\mathrm{I}_{\mathrm{a}}$ is current drawn by coil, and $d x / d t$ is velocity of coil.

Linear voice coil actuator can be further used as velocity sensor and above equation can be further simplified as velocity sensor as below,

$$
\frac{d x}{d t}=\frac{1}{\alpha}\left(V_{s S}-R_{i} I_{a}-L_{i} \frac{d I_{a}}{d t}\right)
$$

Integrating above equation we can easily estimate position of coil and position estimator equation can be given by relation,

$$
x=\frac{1}{\alpha} \int\left(V_{s S}-R_{i} I_{a}-L_{i} \frac{d I_{a}}{d t}\right) d t
$$


Thus, from above we can easily adopt this algorithm for measurement of displacement of motion stage which is shown in figure 8 below.

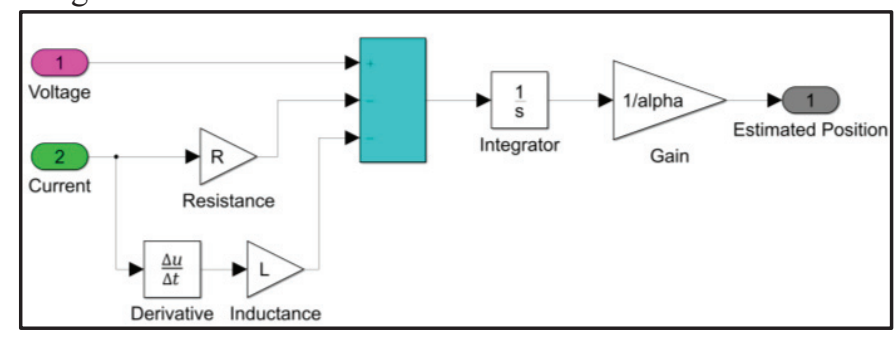

Figure 8: Position Estimator Algorithm in MATLAB Simulink

Similar sort of concept is used for stroke estimation in DFM. Here we need to accurately measure current and voltage drawn by coil in real time. Above discussion shows that linear voice coil actuator can work as displacement sensor to obtain the position information without any extra sensor is adopted.

Figure 9 shows the mechatronic interface done for implementation of position estimator algorithm. Additional circuit is integrated to VCM for sensing current and voltage drawn by VCM.

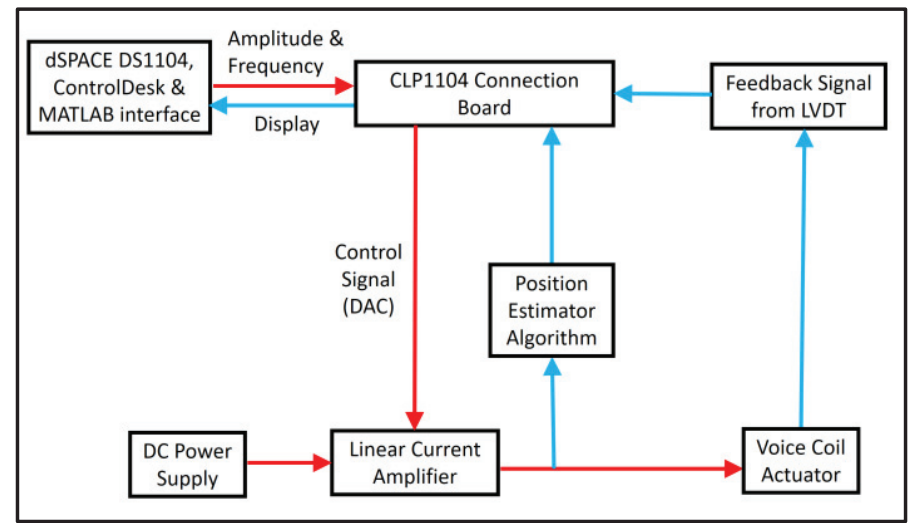

Fig. 9: Voltage and Current Monitoring System

This concept is used in present research work for sensorless measurement of position of motion stage of flexural mechanism. Measurement of voltage and current across coil is experimentally carried out using suitable sensing circuit and these collected data is further processed. Position estimator algorithm needs a current \& voltage signal. Estimated position from position estimator is compared with actual position of motion stage.

\section{RESULTS \& DISCUSSION}

The actual position output from output encoder and predicted position by algorithm is compared with the input reference signal provided and the difference between both is determined to verify the accuracy of the developed position estimator algorithm with the position optical encoder.

From figures 10 and 11, it has been observed that scanning speed achiezved is $0.6 \mathrm{~mm} / \mathrm{sec}$ at $1 \mathrm{~Hz}$ frequency. It shows error to $25 \mu \mathrm{m}$. whatever error is present is because of noise present in the electrical systems.

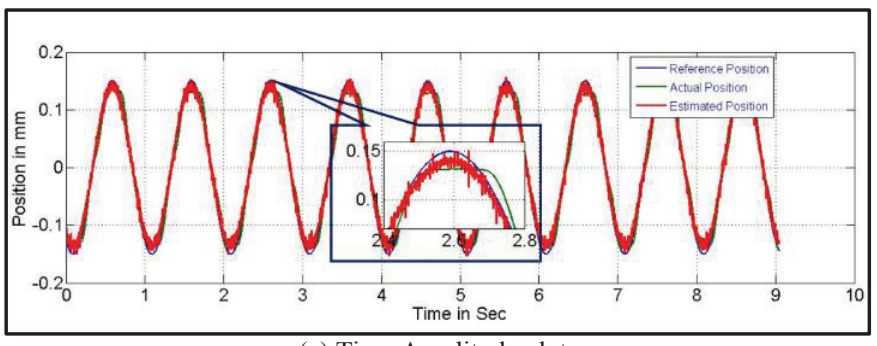

(a) Time Amplitude plot

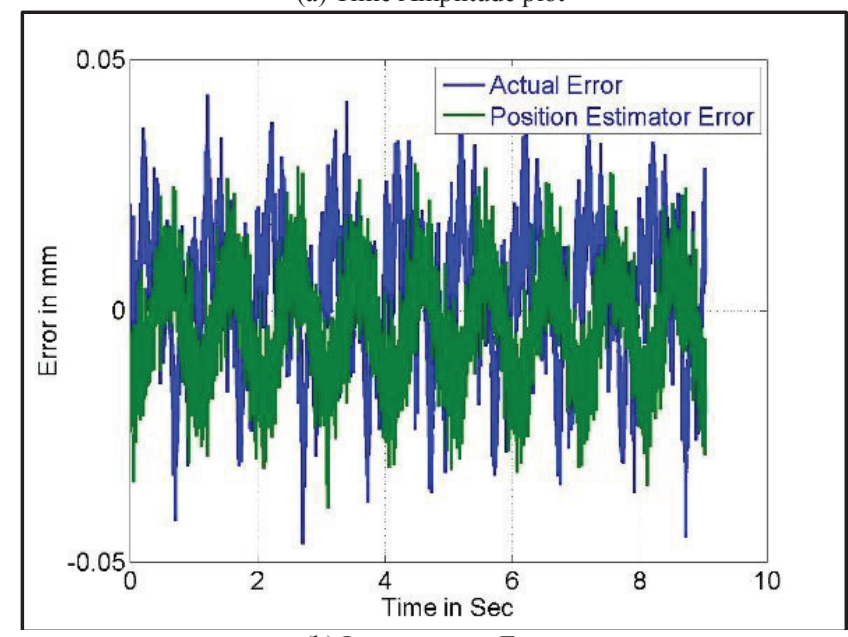

(b) Instantaneous Error

Fig.10: Results of Position Estimator at Amplitude $=0.15 \mathrm{~mm}$ Frequency $=1 \mathrm{~Hz}$

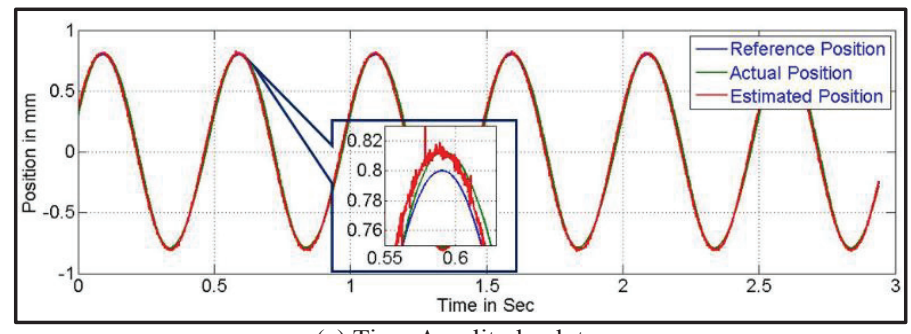

(a) Time Amplitude plot

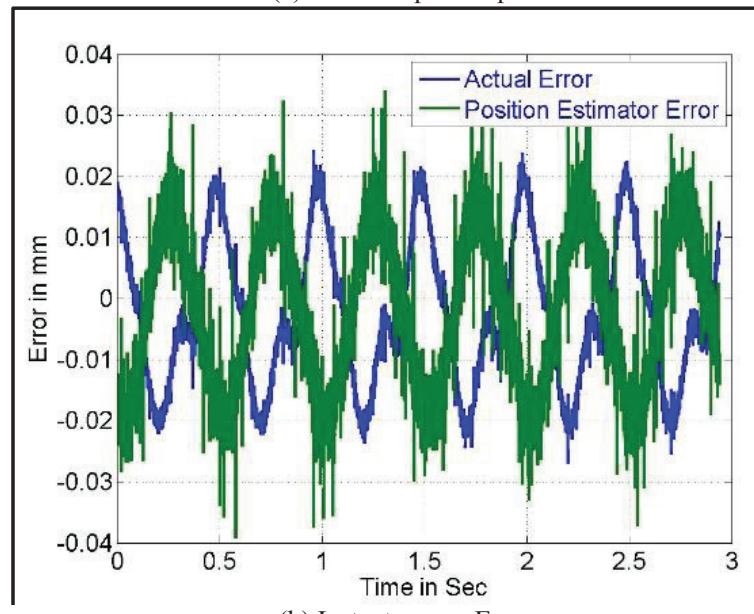

(b) Instantaneous Error

Fig.11: Results of Position Estimator at Amplitude $=0.8 \mathrm{~mm}$ Frequency $=2 \mathrm{~Hz}$

\section{CONCLUSION}

Voice coil motor for high precision applications is successfully designed and fabricated. Further it is integrated with dSPACE DS1104 R\&D controller and LVDT for 
calibration purpose. The position estimator algorithm is developed in Simulink in integration with PID controller to obtain minimum error. Due experimentation shows there is a very good agreement of $99.2 \%$ in between the measured LVDT output and predicted position by algorithm. Further experimentation can be carried out based on varying the type of input such as step input, ramp input, etc. A generic algorithm can be developed further which can work under any type of input signal.

\section{REFERENCES}

[1] S. Awtar, "Synthesis and analysis of parallel Kinematic XY flexure mechanisms," Massachusetts Inst. Technol. Dept Mech. Eng., vol. 126, no. December 2003, p. 109, 2004.

[2] S. Awtar and A. Slocum, "A large range XY flexure stage for nanopositioning," Proc. 5th Euspen Int. Conf., no. May, pp. 491-494, 2005.

[3] S. Awtar, K. Shimotsu, and S. Sen, "Elastic Averaging in Flexure Mechanisms: A Three-Beam Parallelogram Flexure Case Study,” J. Mech. Robot., vol. 2, no. 4, pp. 41006-41012, 2010.

[4] S. Awtar and A. H. Slocum, "Constraint-Based Design of Parallel Kinematic XY Flexure Mechanisms," J. Mech. Des., vol. 129 , no. 8, p. 816, 2007.

[5] C. Cheung and W. . Lee, "A theoretical and experimental investigation of surface roughness formation in ultra-precision diamond turning," Int. J. Mach. Tools Manuf., vol. 40, no. 7, pp. 979-1002, 2000.

[6] Y. M. Choi and D. G. Gweon, "A high-precision dual-servo stage using halbach linear active magnetic bearings," IEEE/ASME Trans. Mechatronics, vol. 16, no. 5, pp. 925-931, 2011.

[7] S. Ito and G. Schitter, "Comparison and classification of highprecision actuators based on stiffness influencing vibration isolation," IEEE/ASME Trans. Mechatronics, vol. 21, no. 2, pp. 1169-1178, 2016.

[8] S. Ito, J. Steininger, and G. Schitter, "Low-stiffness dual stage actuator for long rage positioning with nanometer resolution," in Mechatronics, 2015, vol. 29, pp. 46-56.

[9] J. M. Huang, A. Q. Liu, Z. L. Deng, Q. X. Zhang, J. Ahn, and A. Asundi, "An approach to the coupling effect between torsion and bending for electrostatic torsional micromirrors," Sensors Actuators, A Phys., vol. 115, no. 1, pp. 159-167, 2004.

[10] J. Freire Gómez, J. D. Booker, and P. H. Mellor, "2D shape optimization of leaf-type crossed flexure pivot springs for minimum stress," Precis. Eng., vol. 42, pp. 6-21, 2015.
[11] J. Pinskier, B. Shirinzadeh, L. Clark, Y. Qin, and S. Fatikow, "Design, development and analysis of a haptic-enabled modular flexure-based manipulator," Mechatronics, vol. 40, pp. 156166, 2016.

[12] S. P. Deshmukh, H. Zambare, K. Mate, M. S. Shewale, and Z. Khan, "System identification and PID implementation on double flexural manipulator," in 2015 International Conference on Nascent Technologies in the Engineering Field, ICNTE 2015 Proceedings, 2015.

[13] S. Xiao and Y. Li, "Optimal design, fabrication, and control of an $\mathrm{XY}$ micropositioning stage driven by electromagnetic actuators," IEEE Trans. Ind. Electron., vol. 60, no. 10, pp. 4613-4626, 2013.

[14] J. Qu, W. Chen, J. Zhang, and W. Chen, "A piezo-driven 2-DOF compliant micropositioning stage with remote center of motion," Sensors Actuators, A Phys., vol. 239, pp. 114-126, 2016.

[15] Z. Zhang and H. Hu, "Flexural mechanism design analysis for a new piezoelectric inchworm actuator," in 2009 International Conference on Measuring Technology and Mechatronics Automation, ICMTMA 2009, 2009, vol. 1, pp. 98-101.

[16] E. Du, H. Cui, and Z. Zhu, "Review of nanomanipulators for nanomanufacturing," Int. J. Nanomanuf., vol. 1, no. 1, pp. 83104, 2006.

[17] J. Pinskier, B. Shirinzadeh, L. Clark, Y. Qin, and S. Fatikow, "Design, development and analysis of a haptic-enabled modular flexure-based manipulator," Mechatronics, vol. 40, pp. 156166, 2016.

[18] M. Olfatnia, L. Cui, P. Chopra, and S. Awtar, "Large range dual-axis micro-stage driven by electrostatic comb-drive actuators," J. Micromechanics Microengineering, vol. 23, no. 10, 2013.

[19] J. J. Kim, Y. M. Choi, D. Ahn, B. Hwang, D. G. Gweon, and J. Jeong, "A millimeter-range flexure-based nano-positioning stage using a self-guided displacement amplification mechanism," Mech. Mach. Theory, vol. 50, pp. 109-120, 2012.

[20] J. Pinskier, B. Shirinzadeh, L. Clark, Y. Qin, and S. Fatikow, "Design, development and analysis of a haptic-enabled modular flexure-based manipulator," Mechatronics, vol. 40, pp. 156$166,2016$.

[21] S. S. Mulik, S. P. Deshmukh, M. S. Shewale, H. B. Zambare, and A. P. Sundare, "Design and implementation of position estimator algorithm on double flexural manipulator," in 2017 International Conference on Nascent Technologies in Engineering, ICNTE 2017 - Proceedings, 2017. 